\title{
Caprini venous thromboembolism risk assessment permits selection for postdischarge prophylactic anticoagulation in patients with resectable lung cancer
}

\author{
Krista J. Hachey, MD, ${ }^{\mathrm{a}}$ Philip D. Hewes, MD, MPH, ${ }^{\mathrm{b}}$ Liam P. Porter, BS, ${ }^{\mathrm{b}}$ Douglas G. Ridyard, BS, \\ Pamela Rosenkranz, RN, MEd, ${ }^{\mathrm{a}}$ David McAneny, MD, ${ }^{\mathrm{a}}$ Hiran C. Fernando, MBBS, ${ }^{\mathrm{c}}$ and \\ Virginia R. Litle, MD
}

\begin{abstract}
Objective: Postoperative venous thromboembolism (VTE) creates an 8-fold increase in mortality after lung resection. About one third of postoperative VTEs occur after discharge. The Caprini risk assessment model has been used by other specialties to calculate the risk of a VTE. Patients deemed high risk by the model are candidates for prophylactic anticoagulation after discharge, reducing the VTE risk by $60 \%$. Our primary aims were to determine the frequency of VTE events and evaluate whether the Caprini model could risk-stratify patients.
\end{abstract}

Methods: Patients undergoing lung cancer resections during 2005 to 2013 were evaluated. Exclusion criteria were preoperative filter and therapeutic anticoagulation. A total of 232 patients were reviewed and Caprini scores calculated. Subjects were risk stratified into groups of low risk (0-4), moderate risk (5-8), and high risk $(\geq 9)$. Occurrence of VTE events (deep vein thrombosis; pulmonary embolism) were identified by imaging.

Results: The 60-day VTE incidence was 5.2\% (12 of 232); 33.3\% occurred postdischarge $(n=4)$. Half (6 of 12$)$ were pulmonary emboli, 1 of which caused a death, in an inpatient with a score of 16. The VTE incidence increased with Caprini score. Scores in the low, moderate, and high risk groups were associated with a VTE incidence of $0 \%, 1.7 \%$, and $10.3 \%$, respectively. With a high risk score cutoff of 9 , the sensitivity, specificity, and accuracy are $83.3 \%, 60.5 \%$, and $61.6 \%$, respectively.

Conclusions: One third of VTE events occurred after discharge. Postoperative VTE incidence was correlated with increasing Caprini scores. Patients in the high risk group had an incidence of $10.3 \%$. Elevated scores may warrant extended chemoprophylaxis for patients after discharge. (J Thorac Cardiovasc Surg 2016;151:37-44)

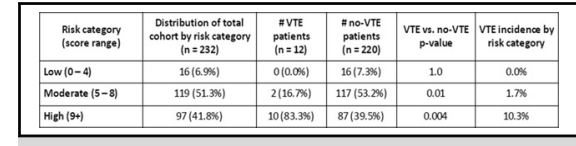

Distribution of patients and overall venothromboembolism (VTE) incidence by risk category. Values are $\mathrm{n}$ $(\%)$, unless otherwise indicated. "VTE patients" had a VTE event; "No-VTE patients" did not have a VTE event.

\section{Central Message}

Postresection venothromboembolic events were correlated with high scores on a riskassessment model for selecting extended prophylaxis.

\section{Perspective}

The risk of death from a postoperative VTE can reach $20 \%$ in some series of lung cancer patients. One third of the VTEs occur after discharge. Our study demonstrated the predictive ability of the Caprini risk-assessment model to allow risk stratification of patients after lung resection, for extended preventive anticoagulation after discharge in those at highest risk.

See Editorial Commentary page 45 .

See Editorial page 18.

\footnotetext{
From the ${ }^{\mathrm{a}}$ Department of Surgery, ${ }^{\mathrm{b}} \mathrm{S}$ chool of Medicine, and ${ }^{\mathrm{c}}$ Division of Thoracic Surgery, Boston University School of Medicine, Boston, Mass.

The Clinical and Translational Science Institute at Boston University is funded by the National Institutes of Health (NIH) Clinical and Translational Science Award program (grant U54TR001012), which is led by the NIH National Center for Advancing Translational Sciences.

Read at the 95th Annual Meeting of The American Association for Thoracic Surgery, Seattle, Washington, April 25-29, 2015.

Read at the 41st Annual Meeting of The Western Thoracic Surgical Association, Whistler, British Columbia, Canada, June 24-27, 2015.

Received for publication May 1, 2015; revisions received July 31, 2015; accepted for publication Aug 8, 2015; available ahead of print Sept 17, 2015.

Address for reprints: Virginia R. Litle, MD, Division of Thoracic Surgery, Department of Surgery, Boston University School of Medicine, 88 E Newton St, Robinson B-402, Boston, MA 02118 (E-mail: Virginia.litle@bmc.org).

$0022-5223 / \$ 36.00$

Copyright (c) 2016 by The American Association for Thoracic Surgery

http://dx.doi.org/10.1016/j.jtcvs.2015.08.039
}

丹 Supplemental material is available online.

Postoperative venous thromboembolism (VTE) after lung resection for cancer leads to a nearly 8 -fold increase in mortality, higher than that reported after esophagectomy and major abdominal and pelvic operations. ${ }^{1}$ Furthermore, as many as one third of postoperative VTE events occur after discharge, with risk persisting for $>30$ days. $^{2-8}$ As a result, new strategies are necessary to identify patients who are at increased risk for perioperative VTE and may benefit from extended prophylaxis with agents such as low molecular weight heparin. 


$$
\begin{aligned}
& \text { Abbreviations and Acronyms } \\
& \text { CI = confidence interval } \\
& \text { DVT }=\text { deep vein thrombosis } \\
& \text { IQR }=\text { interquartile range } \\
& \text { LOS }=\text { length of stay } \\
& \text { OR }=\text { odds ratio } \\
& \text { PE }=\text { pulmonary embolism } \\
& \text { VTE }=\text { venous thromboembolism }
\end{aligned}
$$

Multicenter trials in abdominal and pelvic cancer surgery, and within general and orthopedic surgical populations, demonstrate that extended courses of chemoprophylaxis with these heparin products, such as enoxaparin sodium, for as long as 30 postoperative days, can reduce VTE rates by as much as $60 \%$ without an increase in adverse bleeding events. ${ }^{3-5,9}$ Considering the costs, inconvenience, and potential side effects associated with prolonged prophylactic anticoagulation, the use of a VTE risk assessment tool might selectively apply this intervention to only those patients at high risk.

The Caprini VTE risk assessment model is an individualized risk screening tool that has been evaluated in multiple specialties, including general, vascular, and plastic surgery, as well as gynecologic oncology.,10-13 The American College of Chest Physicians currently includes a modified Caprini model for VTE risk stratification among abdominal and pelvic cancer patients to identify candidates for prolonged prophylaxis although no guidelines have been developed for risk-based extended courses of chemoprophylaxis in thoracic surgery patients. ${ }^{14}$

The Caprini model is comprised of approximately 40 risk factors, including, but not limited to, duration of operation, personal or family history of VTE, body mass index $\geq 30 \mathrm{~kg} / \mathrm{m}^{2}$, and malignancy. A patient's risk factor score can be calculated throughout the hospitalization, but it is most important to determine it at the time of discharge. The total score is used to place individuals into 1 of 3 main risk categories: low (scores 0-4); moderate (5-8); and high $(\geq 9)$. Although not yet widely adopted, a modified Caprini model is integrated into the electronic medical record at our institution, where the risk assessment protocol, in conjunction with early mobility measures, was shown to reduce postoperative VTE rates by as much as $80 \%$ for general and vascular surgical services. ${ }^{11}$ With these services, moderate- and high-risk patients, respectively, are candidates for 10 and 30 days of total postoperative anticoagulant prophylaxis.

This risk assessment model has been implemented for our thoracic surgery patients only recently, and this article does not include patients managed per the model protocol. In this study, we sought to determine the 60-day incidence of postoperative VTE in patients who underwent lung cancer resection. In addition, we calculated the Caprini scores for these patients, to determine whether the model could identify patients at high VTE risk who might benefit from an extended course of prophylaxis.

\section{METHODS}

This retrospective study was approved by the Boston University Medical Center Institutional Review Board. Patients who underwent segmentectomy, lobectomy, or pneumonectomy for lung cancers within the Division of Thoracic Surgery were identified between June 2005 and June 2013 ( $n=309$ ). Pertinent cases were selected based on current procedural terminology codes for open and minimally invasive operations, and all cases were included that matched International Classification of Diseases (9th edition) codes for non-small cell lung cancers and small cell lung cancers.

All included patients had evidence documenting at least 60-day follow-up and had received routine postoperative, prophylactic, subcutaneous, unfractionated heparin 3 times daily, and/or intermittent pneumatic compression during the hospitalization. Low molecular weight heparin was not used as inpatient prophylaxis. Patients were excluded based on presence of any of the following criteria: lost to follow-up or missing records $(n=42)$; deceased due to non-VTE causes before 60 days after surgery $(n=7)$; multiple operations after the first $(n=5)$; preoperative inferior vena cava filter placement $(n=6)$; and hospital discharge on therapeutic anticoagulation for indications not related to postoperative VTE $(\mathrm{n}=17)$. A total of 232 patient records were subsequently analyzed.

The definition used for a VTE event was any pulmonary embolism (PE) or deep vein thrombosis (DVT) identified via clinical imaging studies (ie, computed tomography pulmonary angiogram or duplex ultrasound) and treated with therapeutic anticoagulation or inferior vena cava filter. Caprini risk factors were recorded based on the modified scoring system used at Boston Medical Center, ${ }^{11}$ and patients were stratified into 1 of 3 risk categories: low (scores 0-4), moderate (5-8), and high ( $\geq 9)$. The last 2 categories are currently linked to recommendations for prophylaxis extending beyond discharge. Risk factors were included up until the date of a VTE (for inpatient VTE cases) or until the date of discharge (for outpatient VTE and patients without VTE). The 60-day VTE incidence was determined based on the number of identified VTEs with respect to the total included cohort.

Statistical comparison of patient samples of those who had, versus did not have, VTE was accomplished using the 2-sample $t$ test, the Fisher exact test, the Wilcoxon rank sum test, and $\chi^{2}$ analysis, as appropriate. Logistic regression models were used to assess the relationship between raw Caprini scores or risk categories and the probability of postoperative VTE. The following potential confounders in these models were assessed: baseline cohort characteristics, fiscal year of procedure, adherence to inpatient prophylaxis (subcutaneous, unfractionated heparin, and pneumatic compression boots). Hospital length of stay (LOS) was assessed as a potential covariate, because LOS has been associated with increased risk of VTE and has been evaluated in other risk assessment model validation studies. ${ }^{10}$ Significant confounders were included in adjusted logistic regressions. Regression models were assessed with C-statistics for test discrimination and the Hosmer-Lemeshow test for goodness of fit. Linear trends in odds ratios (ORs) were assessed using the Cochran-MantelHaenszel test.

Potential Caprini score thresholds were scrutinized for their predictive ability to isolate the high risk group as dichotomized variables with assessment of sensitivity, specificity, positive predictive value, negative predictive value, and $\mathrm{C}$-statistics. This evaluation applied an ad hoc criterion for threshold selection (eg, matching to existing Caprini risk categories and maximization of $\mathrm{C}$-statistic values), rather than an inferential one; thus, no adjustment for multiple testing was needed. 


\section{RESULTS \\ Incidence of Venous Thromboembolism and Hospital Length of Stay}

The 60-day postoperative VTE incidence was 5.2\% (12 of 232). One third of VTE events occurred after discharge, with an incidence of $1.7 \%$ within the total cohort (4 of 232). All 4 patients who had VTE after discharge (3 PE; 1 lowerextremity DVT) were symptomatic and were treated with therapeutic anticoagulation. Of the inpatient VTE events, 3 were PEs, accounting for $50 \%$ (6 of 12) of the total VTE complications. Two of the PEs affected main branch pulmonary arteries; 3 involved segmental pulmonary arteries. One patient was diagnosed at an outside hospital, with no specification of anatomic location.

All PEs were associated with clinical manifestations, ranging from shortness of breath, chest pain, and oxygen desaturation, to hypotension with the need for ventilatory support. Of the 5 patients with DVT diagnosed during the hospitalization, 1 had a presumed PE but was too clinically unstable to undergo a computed tomography pulmonary arteriogram. One patient died of a PE during the hospitalization, after a pneumonectomy.

The median time from operative day to VTE event was 10 days (14.5; interquartile range [IQR]: 4-37) (Table 1). For inpatient VTE events $(\mathrm{n}=8)$, the median time to
VTE was 7 days (IQR 9, range 4-21), whereas the median time to VTE event in the outpatient VTE group $(\mathrm{n}=4)$ was 20 days (IQR 13.5, range 12-37). The median LOS for VTE patients was 13.5 days (IQR 28). For inpatient events, the median LOS was 24.5 days (IQR 28, range 663) and for outpatient events, the median LOS was 12 days (IQR 4, range 7-15). Furthermore, the median interval between hospital discharge and VTE was 8 days in the outpatient VTE group (IQR 9.5).

The median hospital LOS in the VTE group was significantly different than in the no-VTE group $(P<.001)$ (Table 2). Furthermore, a higher number of total hospital days was associated with an increased OR for VTE of 1.1 (95\% confidence interval $[\mathrm{CI}] 1.05-1.18, P<.001$ ). No significant differences were found between the VTE and the no-VTE groups based on gender, body mass index, histologic diagnosis, operation type, or prevalence of inpatient prophylaxis. Additionally, no significant difference was found between the number of open operations in the 2 groups, although $68.6 \%$ of no-VTE cases were open operations, versus $91.7 \%$ in the VTE group $(P=.11)$.

\section{Caprini Risk Assessment}

The distributions of Caprini scores in the VTE and noVTE groups were significantly different based on the

TABLE 1. Postoperative venous thromboembolism (VTE) cases $(\mathbf{n}=12)$

\begin{tabular}{|c|c|c|c|c|c|c|}
\hline Patient \# & Surgical procedure & $\begin{array}{l}\text { VTE } \\
\text { type }\end{array}$ & $\begin{array}{l}\text { Time to } \\
\text { VTE (d) }\end{array}$ & $\begin{array}{c}\text { Total hospital } \\
\text { LOS (d) }\end{array}$ & VTE symptoms & VTE location \\
\hline \multicolumn{7}{|c|}{ Inpatient VTE event } \\
\hline 1 & Open lobectomy & DVT & 4 & 6 & Swelling & Duplex ultrasound: gastrocnemius vein \\
\hline 2 & Open pneumonectomy & $\mathrm{PE}$ & 4 & 9 & Hypotension; reintubation; death & $\begin{array}{l}\text { Autopsy: large PE main branch PA } \\
\text { Duplex ultrasound: common femoral, } \\
\text { femoral, profunda femoral, and } \\
\text { popliteal veins }\end{array}$ \\
\hline 3 & VATS lobectomy & $\mathrm{PE}$ & 5 & 32 & Desaturation; reintubation & CTPA: segmental PA \\
\hline 4 & Open lobectomy & PE & 6 & 17 & Desaturation; shortness of breath & CTPA: segmental PA \\
\hline 5 & Open segmentectomy & DVT & 8 & 10 & Swelling & $\begin{array}{l}\text { Duplex ultrasound: common femoral, } \\
\text { superficial femoral, profunda } \\
\text { femoral, and popliteal veins }\end{array}$ \\
\hline 6 & Open lobectomy & DVT & 8 & 43 & Swelling & $\begin{array}{l}\text { Duplex ultrasound: internal jugular and } \\
\text { brachial veins }\end{array}$ \\
\hline 7 & Open lobectomy & DVT & 19 & 32 & Shoulder pain & $\begin{array}{l}\text { Duplex ultrasound: subclavian and } \\
\text { axillary veins }\end{array}$ \\
\hline 8 & Open lobectomy & DVT & 21 & 64 & $\begin{array}{l}\text { Desaturation; hemodynamic } \\
\text { instability; lower-extremity } \\
\text { swelling }\end{array}$ & $\begin{array}{l}\text { Duplex ultrasound: common femoral and } \\
\text { internal jugular veins } \\
\text { Echocardiogram: dilated, hypokinetic RV }\end{array}$ \\
\hline \multicolumn{7}{|c|}{ Postdischarge VTE event } \\
\hline 9 & Open lobectomy & $\mathrm{PE}$ & 12 & 7 & Desaturation & Unknown - outside hospital CTPA \\
\hline 10 & Open lobectomy & $\mathrm{PE}$ & 19 & 12 & Chest pain & $\begin{array}{l}\text { CTPA: distal main PA extending to upper } \\
\text { and lower lobes }\end{array}$ \\
\hline 11 & Open lobectomy & DVT & 21 & 12 & Swelling & Duplex ultrasound: common femoral vein \\
\hline 12 & Open lobectomy & $\mathrm{PE}$ & 37 & 15 & Shortness of breath & CTPA: segmental PA \\
\hline
\end{tabular}

All patients were classified as high risk per the Caprini risk assessment, except for patients 1 and 12, who were classified as moderate risk. The time to VTE is measured from the day of surgery. The VTE diagnoses were verified through review of CTPA or duplex ultrasound results, except for patient 9, who had an outpatient VTE event at an outside hospital. For patient 8 , PE was clinically suspected based on echocardiogram findings. VTE, Venous thromboembolism; LOS, length of stay; $D V T$, deep vein thrombosis; PE, pulmonary embolism; $P A$, pulmonary artery; VATS, video-assisted thoracoscopic surgery; $C T P A$, computed tomography pulmonary angiogram; $R V$, right ventricle. 
TABLE 2. Baseline characteristics of lung resection cohort by VTE status

\begin{tabular}{|c|c|c|c|}
\hline Baseline characteristic & $\begin{array}{l}\text { No-VTE } \\
(n=220)\end{array}$ & $\begin{array}{c}\text { VTE } \\
(\mathbf{n}=12)\end{array}$ & $\begin{array}{c}P \\
\text { valu }\end{array}$ \\
\hline Age, mean (SD), (y) & $64.36(11.0)$ & $63.83(10.2)$ & .87 \\
\hline Gender & & & .1 \\
\hline Male & $92(41.8)$ & $8(66.6)$ & \\
\hline Female & $128(58.2)$ & $4(33.3)$ & \\
\hline $\begin{array}{l}\text { Body mass index, } \\
\text { mean }(\mathrm{SD})\left(\mathrm{kg} / \mathrm{m}^{2}\right)\end{array}$ & $27.42(7.02)$ & $27.38(5.05)$ & .98 \\
\hline \multicolumn{4}{|l|}{ Pathologic diagnosis } \\
\hline Adenocarcinoma & $120(54.5)$ & $7(58.3)$ & 1.0 \\
\hline Squamous cell carcinoma & $58(26.4)$ & $4(33.3)$ & .74 \\
\hline Small cell carcinoma & $6(2.7)$ & $0(0.0)$ & 1.0 \\
\hline Other non-small cell carcinoma & $36(19.1)$ & $1(8.3)$ & .7 \\
\hline \multicolumn{4}{|l|}{ Extent of disease } \\
\hline pN0 & $168(76.4)$ & $10(83.3)$ & .7 \\
\hline $\mathrm{pN} 1$ & $30(13.6)$ & $1(16.7)$ & 1.0 \\
\hline $\mathrm{pN} 2$ & $18(8.1)$ & $0(0.0)$ & .6 \\
\hline pM1 & $4(1.8)$ & $0(0.0)$ & 1.0 \\
\hline \multicolumn{4}{|l|}{ Procedure } \\
\hline Lobectomy & $186(84.5)$ & $10(83.3)$ & .9 \\
\hline Pneumonectomy & $16(7.3)$ & $1(8.3)$ & 1.0 \\
\hline Segmentectomy & $18(8.2)$ & $1(8.3)$ & 1.0 \\
\hline \multicolumn{4}{|l|}{ Open procedure } \\
\hline Thoracotomy & $151(68.6)$ & $11(91.7)$ & .11 \\
\hline Median length of stay (d) (IQR) & $8(6)$ & $13.5(22.3)$ & $<.00$ \\
\hline \multicolumn{4}{|l|}{ Inpatient VTE prophylaxis } \\
\hline Routine pharmacologic & $202(91.8)$ & $12(100.0)$ & .61 \\
\hline $\begin{array}{l}\text { Intermittent pneumatic } \\
\text { compression }\end{array}$ & $202(91.8)$ & $12(100.0)$ & .61 \\
\hline
\end{tabular}

Values are $\mathrm{n}(\%)$, unless otherwise indicated. Other non-small cell carcinomas observed: bronchioloalveolar (no-VTE, $\mathrm{n}=12$ ); large cell carcinoma (no-VTE, $\mathrm{n}=9$ ); mixed or other (no-VTE, $\mathrm{n}=15$; VTE, $\mathrm{n}=1$ ). VTE, Venous thromboembolism; $S D$, standard deviation; $I Q R$, interquartile range.

Wilcoxon rank sum test $(P<.001)$. The net VTE incidence increased with higher Caprini scores $(P$ for trend $<.001)$. A higher Caprini score is associated with a higher OR for VTE of 1.5 (95\% CI 1.19-1.78, $P<.001)$. Adjusting for total LOS, a higher Caprini score is associated with an increased OR of VTE of $1.32(95 \%$ CI 1.04-1.67, $P=.02)$. $\mathrm{C}$-statistics for the association between Caprini score and the probability of VTE were 0.78 and 0.84 in the unadjusted and total LOS-adjusted models, respectively, and Hosmer-Lemeshow goodness-of-fit tests were satisfied for both models (Table E1). Furthermore, a higher Caprini risk category was associated with an increased OR for
VTE of $7.02(95 \%$ CI $1.55-31.7, P=.01)$ on univariate analysis. Adjusting for LOS, the OR for VTE is 3.86 (95\% CI 0.78-19.0, $P=.01)$.

Of the total cohort, $41.8 \%$ had scores in the high risk category; $51.3 \%$ had scores in the moderate risk category; and $6.9 \%$ had scores in the low risk category (Table 3). The overall VTE incidence in the high risk category was $10.3 \%$, compared with $1.7 \%$ and $0.0 \%$ in the moderateand low risk groups, respectively $(P$ for trend $=.004)$. In the VTE group, $83.3 \%$ were high risk, compared with $39.5 \%$ in the no-VTE group $(P=.004)$. Of the 2 VTE cases in the moderate risk group, 1 was an inpatient with DVT identified on postoperative day 4; the other was a nonocclusive thrombus found adjacent to the lobectomy staple line, on postoperative day 37, characterized as a potential postsurgical thrombus.

Scrutinizing the high risk score cutoff of 9 (currently used at our institution on other surgery services) showed that the sensitivity was $83.3 \%$ (95\% CI $58.3 \%-100 \%$ ); specificity was $60.5 \%$ (95\% CI $54.4 \%-67.3 \%)$; accuracy was $61.6 \%$; and the C-statistic was 0.72 . The positive predictive value was $10.3 \%$, and the negative predictive value was $98.5 \%$. The highest $\mathrm{C}$-statistic value was 0.73 , with a cutoff of 10 for the high risk group. The resultant sensitivity, with a cutoff of 10 , was $75.0 \%(95 \%$ CI $50 \%-100 \%)$; specificity was $69.6 \%$ (95\% CI 64.6\%-76.4\%); and accuracy was $69.8 \%$. The resultant sensitivity with a cutoff of 7 to capture all events was $100.0 \%(95 \%$ CI $100 \%-100 \%)$, but the specificity was only $31.4 \%$ (95\% CI $25 \%-37.3 \%$ ), and accuracy was $34.9 \%$. Similarly, with a score cutoff of 5 , used in another published evaluation ${ }^{10}$ as "highest" risk, the sensitivity remained at $100 \%(95 \%$ CI $100 \%-100 \%)$; however, the specificity was only $7.2 \%$ (95\% CI $4.1 \%-11.0 \%)$. The Caprini risk factors most closely associated with a VTE event in this cohort included postoperative sepsis, a history of VTE, serious acute lung disease (such as acute respiratory disease and pneumonia), as well as congestive heart failure, varicose veins, swollen legs, and central venous access (Table 4).

\section{DISCUSSION}

In this retrospective study of VTE risk stratification in lung resection for cancer, the postoperative VTE incidence was $5.2 \%$, with one third of events occurring after discharge. This study establishes that higher Caprini risk

TABLE 3. Distribution of patients and VTE incidence by risk category

\begin{tabular}{|c|c|c|c|c|}
\hline Risk category (score range) & $\begin{array}{c}\text { Distribution of total cohort } \\
\text { by risk category, } \\
n=232 \\
\end{array}$ & $\begin{array}{c}\text { VTE patients } \\
\text { by risk category, } \\
\quad \mathrm{n}=12 \\
\end{array}$ & $\begin{array}{l}\text { No-VTE patients } \\
\text { by risk category, } \\
\quad n=220 \\
\end{array}$ & $\begin{array}{c}\text { VTE vs no-VTE } \\
P \text { value } \\
\end{array}$ \\
\hline Low $(0-4)$ & $16(6.9)$ & $0(0.0)$ & $16(100.0)$ & 1.0 \\
\hline Moderate (5-8) & $119(51.3)$ & $2(1.7)$ & $117(98.3)$ & .01 \\
\hline $\operatorname{High}(\geq 9)$ & $97(41.8)$ & $10(10.3)$ & $87(89.7)$ & .004 \\
\hline
\end{tabular}

Values are n (\%), unless otherwise indicated. "VTE patients" had a VTE event; "No-VTE patients" did not have a VTE event. VTE, Venous thromboembolism. 
TABLE 4. Prevalence of Caprini risk factors by VTE status

\begin{tabular}{|c|c|c|c|c|c|}
\hline Caprini risk factor & Caprini score & No-VTE $(n=220)$ & $\operatorname{VTE}(\mathbf{n}=12)$ & $\begin{array}{l}\text { Fisher } \\
P \text { value }\end{array}$ & $\begin{array}{l}\text { Logistic } \\
P \text { value }\end{array}$ \\
\hline Age 40-59 (y) & 1 & $66(30.0)$ & $2(16.7)$ & .52 & .33 \\
\hline Abnormal pulmonary function & 1 & $107(48.6)$ & $6(50)$ & 1.0 & .93 \\
\hline Acute myocardial infarction $(<1 \mathrm{mo})$ & 1 & $1(0.5)$ & 0 & 1.0 & 1.0 \\
\hline Body mass index $\geq 30\left(\mathrm{~kg} / \mathrm{m}^{2}\right)$ & 1 & $64(29.1)$ & $4(33.3)$ & .75 & .75 \\
\hline Congestive heart failure $(<1 \mathrm{mo})$ & 1 & $3(1.4)$ & $2(16.7)$ & .02 & .005 \\
\hline History of inflammatory bowel disease & 1 & $1(0.5)$ & 0 & 1.0 & 1.0 \\
\hline History of prior major surgery $(<1 \mathrm{mo})$ & 1 & $8(3.6)$ & 0 & 1.0 & 1.0 \\
\hline Complications of pregnancy* & 1 & $1(0.5)$ & 0 & 1.0 & 1.0 \\
\hline Oral contraceptive use or HRT & 1 & $6(2.7)$ & 0 & 1.0 & 1.0 \\
\hline Sepsis $(<1 \mathrm{mo})$ & 1 & $2(0.9)$ & $3(25)$ & .001 & $<.001$ \\
\hline Serious acute lung disease $(<1 \mathrm{mo})$ & 1 & $33(15.0)$ & $5(41.7)$ & .03 & .02 \\
\hline Swollen legs (current) & 1 & $13(5.9)$ & $3(25.0)$ & .04 & .02 \\
\hline Varicose veins & 1 & $23(10.5)$ & $4(33.3)$ & .04 & .03 \\
\hline Age $60-74(y)$ & 2 & $109(49.5)$ & $8(58.3)$ & .37 & .3 \\
\hline Central venous access & 2 & $61(27.8)$ & $7(58.3)$ & .04 & .03 \\
\hline Confined to bed ( $>72 \mathrm{~h})$ & 2 & $22(10.0)$ & $2(16.7)$ & .36 & .5 \\
\hline Major open surgery ( $\geq 45 \mathrm{~min}$ ) & 2 & $151(68.6)$ & $11(91.7)$ & .11 & .13 \\
\hline Present cancer & 2 & $220(100)$ & $12(100)$ & 1.0 & 1.0 \\
\hline Prior cancer, except nonmelanoma skin & 2 & $50(22.7)$ & $3(25)$ & 1.0 & .86 \\
\hline Age $\geq 75(y)$ & 3 & $41(18.6)$ & $2(16.7)$ & 1.0 & .86 \\
\hline History of VTE & 3 & $3(1.4)$ & $3(25)$ & .002 & $<.001$ \\
\hline Family history of VTE & 3 & $3(1.4)$ & $1(8.3)$ & .2 & .12 \\
\hline Chemotherapy & 3 & $27(12.3)$ & $2(16.7)$ & .65 & .66 \\
\hline Positive anticardiolipin antibody & 3 & $1(0.5)$ & 0 & 1.0 & 1.0 \\
\hline Positive Lupus anticoagulant & 3 & $1(0.5)$ & 0 & 1.0 & 1.0 \\
\hline Acute spinal cord injury $(<1 \mathrm{mo})$ & 5 & $1(0.5)$ & 0 & 1.0 & 1.0 \\
\hline Major surgery $\geq 6 \mathrm{~h}$ & 5 & $1(0.5)$ & $1(8.3)$ & .1 & .04 \\
\hline
\end{tabular}

Values are $\mathrm{n}(\%)$, unless otherwise indicated. VTE, Venous thromboembolism; HRT, hormone replacement therapy. *History of unexplained stillborn infant, recurrent or spontaneous abortion (>3), premature birth with toxemia of pregnancy, or growth-restricted infant.

assessment model scores are correlated with an increased likelihood of VTE events, with an overall VTE incidence of $10.3 \%$ in the high risk group. The accurate identification of patients at risk for VTE, as well as the safety of prolonged prophylaxis and prevention of adverse bleeding events, both important aspects of this VTE prevention protocol. Thus, the current institutional high risk score cutoff of 9 seems to be adequate based on sensitivity and specificity for further validation in lung resection patients. In contrast, the score cutoff of 5 , used in prior validation studies, ${ }^{10,12}$ resulted in an unacceptably low specificity in this study.

The high risk score cutoff of 9 was associated with a negative predictive value of $98.5 \%$; thus, VTE risk stratification could potentially spare approximately $60 \%$ of postoperative lung resection patients from the potential side effects and costs associated with 30-day prophylaxis, tailoring this intervention to those who will likely benefit most. Additionally, the reported reduction in postoperative VTE, by $55 \%-60 \%$ with extended course low molecular weight heparin anticoagulant prophylaxis could result in a significant decrease in health care costs associated with the diagnosis and treatment of VTE complications, which can range from approximately $\$ 11,000-\$ 17,000$ per event, with an additional 5\%-14\% risk of readmission for VTE recurrence. ${ }^{3,4,15}$

Successful implementation of the Caprini risk assessment model, with associated prophylaxis recommendations, has already been demonstrated among general and vascular surgery patients at our institution, with high rates of provider adherence. ${ }^{11}$ The model checklist is integrated into our electronic medical record system, and a patient's risk score is calculated by the care team before and after surgery, and modified as risk factors are acquired during the hospitalization. Risk score calculation is most crucial at the time of discharge, when decisions are made about extended courses of prophylaxis.

The American Society of Clinical Oncology, the European Society for Medical Oncology, and other groups currently recommend consideration of 7 to 10 days of total postoperative prophylaxis for cancer surgery patients. ${ }^{16,17}$ This recommendation is currently applied to moderaterisk patients receiving our general and vascular surgical services, based on Caprini score, with postdischarge anticoagulation prescribed to satisfy the prophylaxis duration. In our lung cancer surgical cohort, we identified a VTE incidence of $1.7 \%$ in the moderate risk group, which 


\begin{tabular}{|c|c|c|}
\hline Pre-operative & Post-operative & Hospital Discharge \\
\hline $\begin{array}{l}\text { - Caprini risk assessment integrated } \\
\text { into pre-op surgical risk screening* } \\
\text { - Patients with Caprini scores } \geq 9 \\
\text { (high risk): consider targeted } \\
\text { screening duplex ultrasound } \\
\text { - Proximal DVT(+): consider IVC } \\
\text { filter. If DVT(-) or calf vein DVT(+), } \\
\text { consider one follow up post-op } \\
\text { ultrasound in high risk patients } \\
\text { - Patient education on VTE risk, } \\
\text { symptoms, prevention }\end{array}$ & $\begin{array}{l}\text { - Caprini risk assessment integrated into } \\
\text { post-op patient care assessment and } \\
\text { updated throughout hospitalization } \\
\text { - Routine inpatient prophylaxis and } \\
\text { compression stockings } \\
\text { - Minimization of acquired Caprini risk } \\
\text { factors: removal of unneeded central lines, } \\
\text { early mobility, etc. } \\
\text { - Patients with Caprini scores } \geq 9 \text { : consider } \\
\text { targeted screening duplex ultrasound } \\
\text { when safe to treat if DVT(+) }\end{array}$ & $\begin{array}{l}\text { - Caprini risk assessment integrated } \\
\text { into discharge planning } \\
\text { - Caprini scores } \geq 9: 30 \text { days total post- } \\
\text { op prophylaxis with LMWH } \\
\text { - Caprini scores } 5-8 \text { (moderate risk): } 10 \\
\text { days total post-op prophylaxis }{ }^{\dagger} \\
\text { - Caprini score 1-4 (low risk): no post- } \\
\text { discharge prophylaxis } \\
\text { - Patient education regarding VTE risk } \\
\text { with prophylaxis adherence follow up }\end{array}$ \\
\hline
\end{tabular}

FIGURE 1. Proposed clinical application of the Caprini venous thromboembolism risk assessment model throughout the preoperative, postoperative, and hospital discharge phases for lung resection patients. DVT, Deep vein thrombosis; IVC, interior vena cava; VTE, venous thromboembolism; $L M W H$, low molecular weight heparin. *Integration into the electronic medical record recommended for access throughout perioperative period. $\dagger$ Enoxaparin $40 \mathrm{mg}$ daily or weight-based dosing. Assess bleeding risks prior to prescribing extended course anticoagulation. łAnticoagulation duration per ASCO recommendations ${ }^{15}$.

included an early inpatient DVT, and a late identification of a nonocclusive pulmonary arterial thrombus near the surgical staple line, which may have been an acute PE or a postsurgical clot. The current American College of Chest Physicians guidelines report that those at "low risk" for VTE have a postoperative rate of approximately $1.5 \%$; they do not recommend anticoagulant prophylaxis for this risk group. ${ }^{14}$ Thus, the clinical impact of prescribing additional postdischarge prophylactic anticoagulation, in lung resection patients who are not considered high risk by Caprini score, is unclear and may benefit from prospective evaluation.

Longer hospitalizations have been shown to confer a 3.4to 11.16-fold increased odds of VTE, compared with shorter ( $<1$ week) hospitalizations. ${ }^{18}$ However, we found that $50 \%$ of VTE cases in our lung cancer resection cohort occurred $\leq 8$ days postoperatively, which is the median total LOS in the no-VTE group. A prolonged median LOS was identified in this study, even in the no-VTE cohort. These findings likely reflect the characteristics and challenges faced by the patient population treated at our large safety net hospital. Delays in hospital discharge after surgery at safety-net hospitals are correlated with increased patient comorbidities and inadequate access to appropriate acute care facilities after hospital discharge. ${ }^{19}$ Nonetheless, most VTE patients had Caprini scores that put them in the high risk category, regardless of the interval between surgery and the VTE event; such categorization is supported by the observation that contributing Caprini risk factors were comprised largely of pertinent medical history (age, body mass index, cancer), and that acquired risk factors seemed to occur relatively early during the postoperative period.

This study demonstrated that symptomatic postoperative VTE events in lung resection patients were detected during hospitalization, despite inpatient prophylaxis. Three early postoperative PEs, resulting in 1 mortality and 1 prolonged intubation for ventilatory support complicated by pneumonia, were associated with high risk Caprini scores (patients 2-4). In ambulatory lung cancer patients, VTE rates as high as $15 \%$ have been reported ${ }^{20}$; thus, preoperative targeted duplex screening ultrasound in the high risk cohort, particularly when significant risk factors such as history of VTE are present, may permit early identification of occult DVT before symptoms are manifested.

Duplex ultrasound screening in asymptomatic patients has been associated with sensitivity and specificity of $61 \%-92 \%$, and $97 \%$, respectively. ${ }^{21}$ However, the accuracy of ultrasound screening in a risk-stratified cancer patient population has not been well studied. Lung resection patients who become high risk postoperatively, as a result of significant acquired risk factors such as sepsis and pneumonia, as well as high risk patients with an initial negative preoperative study or identified calf vein thrombosis, may benefit from 1 postoperative ultrasound when therapeutic anticoagulation indicated by test results could be initiated safely. ${ }^{22}$

Clearly, targeted screening ultrasound in high risk lung resection patients requires prospective evaluation, and a proactive approach to occult VTE identification (Figure 1), throughout the perioperative period, may prove critical in preventing symptomatic VTE, particularly in pneumonectomy patients and other surgical patients who have borderline postoperative pulmonary reserve. Efforts may be conducted to minimize acquired Caprini VTE risk factors by removing unnecessary central vein catheters and ensuring early postoperative mobility. Additionally, elevated body mass index is a VTE risk factor, and evidence suggests that weight-based enoxaparin sodium therapy has improved efficacy compared with standard prophylactic doses, particularly in obese patients. ${ }^{9,23}$ Thus, the risk assessment model may be useful in identifying candidates for enhanced prophylaxis, both 
during hospitalization and in high risk patients after discharge.

Reduction of VTE risk using the risk assessment model protocol may be improved with direct oral anticoagulants, such as rivaroxaban and argatroban. Rivaroxaban was approved by the US Food and Drug Administration in 2011, for postoperative VTE prevention in hip- and kneereplacement surgery, but its use is not well established among nonorthopedic patients. ${ }^{24}$ The Regulation of Coagulation in Orthopedic Surgery to Prevent Deep Venous Thrombosis and Pulmonary Embolism 1, 2, and 3 randomized, double-blind, multicenter trials included a total of 9581 total hip and knee arthroplasty patients. The trials directly compared either enoxaparin sodium (a 40-mg daily injection) or rivaroxaban (10 $\mathrm{mg}$ daily) for $\leq 35$ days (trials 1 and 2). ${ }^{25,26}$

These studies demonstrated a relative risk reduction of as much as $88 \%$ for major VTE (including proximal DVT, nonfatal PE, and death from VTE) in favor of rivaroxaban. Although the difference was not statistically significant, the rate of bleeding with rivaroxaban was higher than it was with enoxaparin sodium in these trials; thus, it may be a caveat to the use of these oral agents, particularly in patients with renal impairment. Post hoc analyses of trials 1-3, just mentioned, report an overall more favorable risk-benefit outcome with rivaroxaban, compared with enoxaparin sodium, including a cost savings of $>\$ 500$ per patient. $^{27,28}$

Limitations of this analysis include the fact that the data collection was retrospective, leading to reliance on documentation and imaging studies to confirm VTEs, complex disease states such as sepsis, and inpatient prophylaxis. Total hospital LOS was assessed as a covariate in logistic regression models because LOS was significantly associated with the probability of VTE. However, usage of LOS as a covariate is limited, because some VTE events occurred prior to hospital discharge, and other postoperative factors may have contributed to total LOS. In addition, the study is limited by sample size and the small number of VTE cases for comparison. Furthermore, given that most cases were lobar resections, findings may not necessarily be extrapolated to sublobar resections or pneumonectomy patients. A few cases were excluded; thus, the VTE risks among patients undergoing resection of lung cancers may have been overestimated in this cohort.

This study is the first to demonstrate the ability of the Caprini risk assessment model to predict VTE in patients after resections of lung cancers. Integration of Caprini risk screening throughout the course of care has the potential to identify patients at greatest risk of developing VTE and can be linked to anticoagulation prophylaxis recommendations, which we are currently evaluating in a prospective quality-improvement study.

\section{Conflict of Interest Statement}

Dr Fernando reports consulting fees for CSA Medical and Galil Medical. All other authors have nothing to disclose with regard to commercial support.

\section{References}

1. Trinh VQ, Karakiewicz PI, Sammon J, Sun M, Sukumar S, Gervais MK, et al. Venous thromboembolism after major cancer surgery: temporal trends and patterns of care. JAMA Surg. 2014;149:43-9.

2. Merkow RP, Bilimoria KY, McCarter MD, Cohen ME, Barnett CC, Raval MV, et al. Post-discharge venous thromboembolism after cancer surgery: extending the case for extended prophylaxis. Ann Surg. 2011;254:131-7.

3. Bergqvist D, Agnelli G, Cohen AT, Eldor A, Nilsson PE, Le Moigne-Amrani A, et al. Duration of prophylaxis against venous thromboembolism with enoxaparin after surgery for cancer. N Engl J Med. 2002;346:975-80.

4. Rasmussen MS, Jorgensen LN, Wille-Jorgensen P, Nielsen JD, Horn A, Mohn AC et al. Prolonged prophylaxis with dalteparin to prevent late thromboembolic complications in patients undergoing major abdominal surgery: a multicenter randomized trial. J Thromb Haemost. 2006;4:2384-90.

5. Hull RD, Pineo GF, Stein PD, Mah AF, MacIsaac SM, Dahl OE, et al. Extended out-of-hospital low-molecular-weight heparin prophylaxis against deep venous thrombosis in patients after elective hip arthroplasty: a systematic review. Ann Intern Med. 2001;135:858-69.

6. Pannucci CJ, Bailey SH, Dreszer G, Wachtman CF, Zumsteg JW, Jaber RM, et al. Validation of the Caprini risk assessment model in plastic and reconstructive surgery patients. J Am Coll Surg. 2011;212:105-12.

7. Huo MH, Munt J. Extended thromboprophylaxis with low-molecular weight heparins after hospital discharge in high-risk surgical and medical patients: a review. Clin Ther. 2009;31:1121-41.

8. Nelson RE, Grosse SD, Waitzman NJ, Lin J, DuVall SL, Patterson O, et al. Using multiple sources of data for surveillance of postoperative venous thromboembolism among surgical patients treated in Department of Veterans Affairs hospitals, 2005-2010. Thromb Res. 2015;135:636-42.

9. Borkgren-Okonek MJ, Hart RW, Pantano JE, Rantis PC, Guske PJ, Kane JM, et al. Enoxaparin thromboprophylaxis in gastric bypass patients: extended duration, dose stratification, and antifactor Xa activity. Surg Obes Relat Dis 2008;4:625-31.

10. Bahl V, Hu HM, Henke PK, Wakefield TW, Campbell DA, Caprini JA. A validation study of a retrospective venous thromboembolism risk scoring method. Ann Surg. 2010;251:244-350.

11. Cassidy MR, Rosenkranz P, McAneny D. Reducing postoperative venous thromboembolism complications with a standardized risk-stratified prophylaxis protocol and mobilization program. J Am Coll Surg. 2014;218:1095-104.

12. Stroud W, Whitworth JM, Miklic M, Schneider KE, Finan MA, Scalici J, et al Validation of a venous thromboembolism risk assessment model in gynecologic oncology. Gynecol Oncol. 2014;134:160-3.

13. Yarlagadda BB, Brook CD, Stein DJ, Jalisi S. Venous thromboembolism in otolaryngology surgical inpatients receiving prophylaxis. Head Neck. 2014;36: 1087-93.

14. Gould MK, Garcia DA, Wren SM, Karanicolas PJ, Arcelus JI, Heit JA, et al. Prevention of VTE in nonorthopedic surgical patients: Antithrombotic Therapy and Prevention of Thrombosis 9th ed: American College of Chest Physicians Evidence-Based Clinical Practice Guidelines. Chest. 2012;141(2 Suppl): e227S-77S.

15. Spyropoulos AC, Lin J. Direct medical cost of venous thromboembolism and subsequent hospital readmission rates: an administrative claims analysis from 30 managed care organizations. J Manag Care Pharm. 2007;13: 475-86.

16. Lyman GH, Khorana AA, Kuderer NM, Lee AY, Arcelus JI, Balaban EP, et al Venous thromboembolism prophylaxis and treatment in patients with cancer: American Society of Clinical Oncology Clinical Practice Guideline Update. J Clin Oncol. 2013;31:2189-204.

17. Mandala M, Falanga A, Roila F. ESMO Guidelines Working Group. Venous thromboembolism in cancer patients: ESMO Clinical Practice Guidelines for the management. Ann Oncol. 2010;21(Suppl 5):v274-6.

18. De Martino RR, Goodney PP, Spangler EL, Wallaert JB, Corriere MA Rzucidlo EM, et al. Variation in thromboembolic complications among patients undergoing commonly performed cancer operations. J Vasc Surg. 2012;55: $1035-41$. 
19. Eslami MH, Rybin D, Doros G, Farber A. Care of patients undergoing vascular surgery at safety net public hospitals is associated with higher cost but similar mortality to nonsafety net hospitals. J Vasc Surg. 2014;60: 1627-34.

20. Connolly GC, Menapace L, Safadjou S, Francis CW, Khorana AA. Prevalence and clinical significance of incidental and clinically suspected venous thromboembolism in lung cancer patients. Clin Lung Cancer. 2013;14: 713-8.

21. Rogers FB, Chipolle MD, Velmahos G, Rozycki G, Luchette FA. Practice management guidelines for the prevention of venous thromboembolism in trauma patients: the EAST practice management guidelines work group. $J$ Trauma. 2002;53:142-64.

22. Wells PS, Anderson DR, Bormanis J, Guy F, Mitchell M, Gray L, et al. Value of assessment of pretest probability of deep-vein thrombosis in clinical management. Lancet. 1997;350:1795-8.

23. Rondina MT, Wheeler M, Rodgers GM, Draper L, Pendleton RC. Weight-based dosing of enoxaparin for VTE prophylaxis in morbidly obese, medically-ill patients. Thromb Res. 2010;125:220-3.

24. FDA expands use of Xarelto to treat, reduce recurrence of blood clots. [news release]. Silver Spring, MD: US Food and Drug Administration; 2012. Available at: http://www.fda.gov/NewsEvents/Newsroom/PressAnnouncements/ucm3266 54.htm.

25. Eriksson BI, Borris LC, Friedman RJ, Haas S, Huisman MV, Kakkar AK, et al. Rivaroxaban versus enoxaparin for thromboprophylaxis after hip arthroplasty. N Engl J Med. 2008;358:2765-75.

26. Kakkar AK, Brenner B, Dahl OE, Eriksson BI, Mouret P, Muntz J, et al. Extended duration rivaroxaban versus short-term enoxaparin for the prevention of venous thromboembolism after total hip arthroplasty: a double-blind, randomized controlled trial. Lancet. 2008;372:31-9.

27. Levitan B, Yuan Z, Turpie AG, Friendman RJ, Homering M, Berlin JA, et al. Benefit-risk assessment of rivaroxaban versus enoxaparin for the prevention of venous thromboembolism after total hip or knee arthroplasty. Vasc Health and Risk Manag. 2014;10:157-67.

28. Duran A, Sengupta N, Diamantopoulos A, Forster F, Kwong L, Lees M. Cost effectiveness of rivaroxaban versus enoxaparin for prevention of post-surgical venous thromboembolism from a US payer's perspective. Pharmacoeconomics. 2012;30:87-101.

Key Words: lung cancer, postoperative care, embolism (venous)

Readers who found these articles interesting may also like to read the following papers found in recent and future issues of our sister publications, Seminars in Thoracic and Cardiovascular Surgery and Operative Techniques in Thoracic and Cardiovascular Surgery!

Original Submission: The 3-Hole Minimally Invasive Esophagectomy: A Safe Procedure Following Neoadjuvant Chemotherapy and Radiation. Rona Spector. Semin Thorac Cardiovasc Surg 2015; Summer; 27(2): 205-215.

Editorial Commentary: With Minimally Invasive Esophagecomty, Thoracic Surgeons Must Avoid Falling Into the Same Trap Again. Thomas Ng. Semin Thorac Cardiovasc Surg 2015; Summer; 27(2):216.

Original Submission: Maximal Oxygen Uptake - Risk Predictor of NSCLC Resection with Comorbid Emphysema: Lessons from NETT. Ian Makey. Semin Thorac Cardiovasc Surg 2015; Summer; 27(2):224-225.

Editorial Commentary: How Can the NETT Provide Guidance in Risk Stratification for Patients with Severe Emphysema and Early Stage NSCLC? Michael Hsin. Semin Thorac Cardiovasc Surg 2015; Summer; 27(2):232-233.

Original Submission: Retrospective Analysis of Lung Transplant Recipients Found to Have Unexpected Lung Cancer in Explanted Lungs. Takahiro Nakajima. Semin Thorac Cardiovasc Surg 2015; Spring; 27(1):9-14.

Editorial Commentary: A New Set of Lungs or a New Pair of Glasses? Dirk E.M. Van Raemdonck. Semin Thorac Cardiovasc Surg 2015; Spring; 27(1):15-16.

State of the Art: Induction Therapy for Mesothelioma. Isabelle Schmitt-Opitz. Semin Thorac Cardiovasc Surg 2015; Summer; 27(2):240-250.

State of the Art: Precision Therapy for Lung Cancer: Tyrosine Kinase Inhibitors and Beyond. David Schrump. Semin Thorac Cardiovasc Surg 2015; Spring; 27(1):36-48. 
TABLE E1. Logistic regression models for Caprini score and Caprini risk category versus probability of VTE

\begin{tabular}{|c|c|c|c|c|}
\hline \multirow[b]{2}{*}{ Measure } & \multicolumn{2}{|c|}{ Caprini score vs probability of VTE } & \multicolumn{2}{|c|}{ Risk category vs probability of VTE } \\
\hline & Univariate & Multivariate & Univariate & Multivariate \\
\hline Caprini score & $1.46(1.19-1.78) P<.001$ & $1.32(1.04-1.67) P=.02$ & - & - \\
\hline Risk category & - & - & $7.02(1.55-31.7) P=.01$ & $3.86(0.78-19.0) P=.1$ \\
\hline Total LOS & - & $1.08(1.02-1.15) P=.01$ & - & $1.09(1.03-1.15) P=.002$ \\
\hline C-statistic & 0.78 & 0.84 & 0.73 & 0.82 \\
\hline \multicolumn{5}{|c|}{ Hosmer-Lemeshow* } \\
\hline$\chi^{2} / \mathrm{df}$ & $6.33 / 8$ & $5.39 / 8$ & $0.04 / 1$ & $4.85 / 8$ \\
\hline$P$ value & .61 & .72 & .84 & .77 \\
\hline
\end{tabular}

